\title{
Currarino syndrome: does the presence of a genetic anomaly correlate with a more severe phenotype? A multicentre study
}

\author{
Sara Costanzo ${ }^{\mathrm{a}, *}$, Luigina Spaccini ${ }^{\mathrm{b}}$, Luca Pio ${ }^{\mathrm{c}}$, Girolamo Mattioli ${ }^{\mathrm{c}, \mathrm{d}}$, Calogero Virgone ${ }^{\mathrm{e}}$, Patrizia Dall'Igna ${ }^{\mathrm{e}}$, \\ Barbara Iacobelli ${ }^{\mathrm{f}}$, Alessandro Inserra ${ }^{\mathrm{f}}$, Giulia Brisighelli ${ }^{\mathrm{g}}$, Anna Maria Fagnani ${ }^{\mathrm{g}}$, Ernesto Leva ${ }^{\mathrm{g}}$, \\ Giulia Giannotti ${ }^{\text {h}}$, Maurizio Cheli ${ }^{\mathrm{h}}$, Paolo Frumento ${ }^{\mathrm{i}}$, Giovanna Riccipetitoni ${ }^{\mathrm{a}}$ \\ a Pediatric Surgery Unit, V. Buzzi Children's Hospital, Milan, Italy \\ ${ }^{\mathrm{b}}$ Genetic Service, V. Buzzi Children's Hospital, Milan, Italy \\ c Pediatric Surgery Department, DINOGMI - University of Genoa, Genoa, Italy \\ d Pediatric Surgery Unit, G. Gaslini Children's Hospital, Genoa, Italy \\ e Pediatric Surgery, Department of Women's and Children's Health, University of Padua, Padua, Italy \\ ${ }^{\mathrm{f}}$ Pediatric Surgery, Bambino Gesù Children's Hospital, Rome, Italy \\ g Pediatric Surgery Unit, Fondazione IRCCS Ca' Granda Ospedale Maggiore Policlinico, Milan, Italy \\ h Pediatric Surgery Unit, ASST Papa Giovanni XXIII, Bergamo, Italy \\ ${ }^{1}$ Unit of Biostatistics, Institute of Environmental Medicine, Karolinska Institutet, Stockholm, Sweden
}

\section{A R T I C L E I N F O}

\section{Article history}

Received 23 December 2016

Received in revised form 11 June 2017

Accepted 13 June 2017

\section{Key words:}

Currarino syndrome

MNX1 gene

Associated anomalies

Genotype-phenotype correlation

\begin{abstract}
A B S T R A C T
Background/purpose: Currarino syndrome (CS) phenotype, initially described as the triad of hemisacrum, anorectal malformation (ARM) and presacral mass, can be extremely variable. The triad is often incomplete and 3 main CS phenotypical subtypes have been described: Complete, Mild and Minimal. Various associated malformations are often present. Mutations in the MNX1 gene are the main genetic background of CS, although they are not present in almost half of the cases. Aim of our study is to analyze the distribution of the 3 CS subtypes and the incidence of associated malformations in a large sample of patients and to add information about the role of the genetic testing in guiding the diagnostic and prognostic evaluation of CS patients.

Methods: A multicentre retrospective data collection was performed. CS patients' phenotype was accurately analyzed according to a diagnostic-therapeutic standardized data collection sheet. The distribution of the three CS types and the frequency of each associated malformation were calculated. The phenotype of the patients with a known genetic anomaly was compared to the phenotype of the population with no genetic diagnosis, in order to determine whether the presence of a known genetic defect could correlate with a more severe CS phenotype. Results: Data from 45 patients were analyzed. Twenty patients (44.5\%) presented a Complete CS type, 19 (42.2\%) a Mild CS and 6 (13.3\%) a Minimal CS. In addition to the classical triad elements, 38 (84.5\%) patients showed associated anomalies. The group of patients who resulted positive for a MNX1 mutation comprised a higher number (56.5\%) of Complete CS cases than the group of patients that did not carry any MNX1 mutation (13\%) $(p=0.0085)$. We could not find any relationship between CS subtype and the number of associated anomalies $(p=0.5102)$.

Conclusions: The presence of a MNX1 mutation seems to correlate with a more severe CS phenotype. MNX1 seems the main responsible for the expression and the severity of the CS triad, while the associated anomalies appear to be prevalently determined by genes sited on different loci. A thorough multidisciplinary diagnostic overview of CS patients should always include genetic counseling and analysis, both in postnatal and prenatal settings. Type of study: Retrospective Study.
\end{abstract}

Level of evidence: II.

(c) 2017 Elsevier Inc. All rights reserved.

\footnotetext{
* Corresponding author at: Pediatric Surgery Department, V. Buzzi Children's Hospital, Via L. Castelvetro 32, 20154 Milano, Italy.

E-mail address: saracostanzo@ymail.com (S. Costanzo).
}

Currarino syndrome (CS; OMIM \#176450) was initially described in 1981 by Guido Currarino, an Italian pediatric radiologist, as the triad of hemisacrum, anorectal malformation (ARM) and presacral mass [1].

Further studies about CS showed that its clinical phenotype can be extremely variable. The triad is often incomplete: many cases present one or two defects only; the sacral anomaly is generally present and 
the syndrome has been classified into 3 different types [2,3]: (1) complete CS: CS presenting the complete triad; (2) mild CS: sacral anomaly associated with one of the other malformations, i.e. ARM or presacral mass; (3) minimal CS: hemisacrum only.

Associated malformations are often present: mainly neural tube defects and other central nervous system (CNS) anomalies, urological and gynecological malformations, but also trisomy 21, Hirschsprung's disease and costal anomalies have been described [2].

CS is considered an autosomal dominant condition, with reduced penetrance and variable expressivity [3]. MNX1 gene (motor neuron and pancreas homeobox 1, HGNC ID: 4979, GenBanK: NM_005515.3), mapped to 7q36, previously named HLXB9, is the causative gene for familial CS. Mutations in the coding sequence of MNX1 gene have been reported in nearly all familial CS cases and in approximately $30 \%$ of CS sporadic patients. More than 80 mutations at the MNX1 locus have been described so far [3].

Our aim is to study the CS phenotype in a large group of patients, analyzing the distribution of the 3 different CS types (Complete, Mild, Minimal), the incidence of associated malformations and the role of the genetic testing in the diagnostic and prognostic evaluation of CS patients.

\section{Materials and methods}

This retrospective multicentre study involved six Italian Pediatric Surgery Units from the following Centers: G. Gaslini Children's Hospital, Genoa; V. Buzzi Children's Hospital, Milan; Fondazione IRCCS Ca' Granda Ospedale Maggiore Policlinico, Milan; ASST Papa Giovanni XXIII, Bergamo; Padua Hospital, Padua; Bambino Gesù Children's Hospital, Rome.

All patients diagnosed, treated and/or followed up for CS at each centre were included in the study.

Data on CS patients were collected by a Physician for each centre according to a diagnostic-therapeutic standardized data collection sheet, created on the basis of the literature available to date.

Collected data included: demographics (patient's ID, date of birth, sex and age at diagnosis), information about familiarity (presence of other CS cases in the family - familial or sporadic CS), consanguinity of parents, genetic study performed and type of mutation/s found.

Details about the phenotype of each patient were obtained; the data collection sheet reported a complete list of the characteristics of each defect: type of sacral anomaly, classified according to Pang's classification [4] (type I - total sacral agenesis with lumbar vertebrae involvement, type II - total sacral agenesis without lumbar vertebrae involvement, type III - subtotal sacral agenesis with S1 present, type IV - hemisacrum, type V - coccyx agenesis); type of anorectal malformation (anorectal stenosis, rectoperineal fistula, rectourethral fistula, rectovestibular fistula, rectocloacal fistula); type of presacral mass (mature teratoma, anterior meningocele, enteric duplication, immature teratoma, cordoma, yolk sac tumor).

Associated anomalies considered were: neural tube defects (tethered cord, filum terminale lipoma, syringomyelia, hydromyelia, diastematomyelia) and possible complications (meningitis, neurological consequences of caudal neural tube defects); other central nervous system anomalies; urological anomalies (ureteral duplication, horseshoe kidney, kidney duplication, vescico-ureteric reflux, renal dysplasia, hypospadias, neurogenic bladder); gynecological anomalies (bicornuate uterus, septate vagina, bifid clitoris); Down's syndrome; Hirschsprung's disease; others (skeletal, cardiac anomalies).

The diagnostic approach, the surgical treatment and follow-up were also examined, even if not relevant for the purpose of this study.

After data collection, the distribution of the three CS types (Complete, Mild, Minimal) and the frequency of each associated malformation could be defined. In a second phase of the analysis we compared the phenotype of the patients with a known genetic anomaly with the phenotype of the population with no genetic diagnosis, in order to determine whether the presence of a genetic defect could correlate or not with a more severe CS phenotype.

Statistical analysis was performed through Chi-squared test.

\section{Results}

Data from 47 patients were collected and analyzed. There were 23 (49\%) males and 24 (51\%) females, with a median age at diagnosis of 1 year (range 0 to 42 years, mean $3.03 \pm 7.17$ ). In 2 (4.2\%) patients, children of mothers affected by CS, the diagnosis was made prenatally through a villocentesis; $11(23.5 \%)$ were diagnosed at birth or by the first month of life, 14 (29.8\%) by 1 year of age and 20 (42.5\%) after 1 year.

Data from 2 patients were highly incomplete and were not considered for the analysis.

Of the 45 patients, 13 (29\%) had one or more relatives diagnosed with CS (familial CS), while 30 (67\%) had a sporadic disease. In 2 cases there were no data about familiarity. No consanguinity between parents was reported in the whole series.

Twenty patients (44.5\%) presented the complete Currarino triad (Complete CS); 19 (42.2\%) showed a Mild CS, with a sacral anomaly associated with an ARM in 4 (9\%) and with a presacral mass in 15 (33\%); 6 (13.3\%) cases could be classified as Minimal CS, with isolated hemisacrum (Fig. 1).

All patients presented a sacral anomaly. The types and prevalence of the sacral anomalies, the ARM and the presacral masses identified are reported in Table 1.

Of the 35 presacral masses, 8 are defined as mixed masses and comprise: 6 associations teratoma/anterior meningocoele (AM), and 1 not defined. No malignant lesions are reported in our series. In one patient, already known for a sacral anomaly type III, tethered cord and filum lipoma, the diagnosis of the presacral mass was made after he developed a gluteal and pararectal abscess with secondary miositis, deriving from an infection of his presacral teratoma. No other complications of presacral masses have been reported.

In addition to the classical triad elements, 38 (84.5\%) out of 45 patients had associated anomalies, that are listed in Table 2 . In 23 cases (51\%) two or more associated anomalies were observed (Table 3). We could not find any relationship between the Currarino subtype and the number of associated anomalies $(p=0.5102)$.

The genetic study was performed in 38/45 patients: 23 (60.5\%) were positive for a MNX1 mutation (Group 1), 15 negative (Group 2). In the group of patients who underwent a genetic study, $100 \%$ of the familial cases and $44 \%$ of the sporadic cases had a MNX1 mutation.

In Group 1, 13 (56.5\%) had a complete form of CS, 9 (39\%) a mild and $1(4.5 \%)$ a minimal form. In Group 2, the complete forms were $2(13 \%)$, the mild 8 (53\%) and the minimal 5 (33\%) (Table $4-p=0.0085$ ).

\section{Discussion}

Since its first definition by Guido Currarino, Currarino triad has been widely studied and it is now recognized as a complex condition, with a variable expression and a number of possible associated conditions, involving different systems and organs, so that the term Currarino Syndrome, initially used by Belloni et al. [5], is now considered more appropriate.

The identification of a familial tendency [6] and a responsible genetic anomaly $[5,7]$ has led to a more thorough understanding of this syndrome, transmissible as an autosomic dominant condition with reduced penetrance and variable expressivity [3,8]. Many different genetic defects of the MNX1 gene have been identified, although no clear correspondence between genotype and phenotype has been shown so far.

We collected a vast series of CS patients to analyze and classify their phenotype, dividing them into three CS subtypes previously described in the literature [2], underlying the most frequent associated conditions 


\section{CS subtypes}

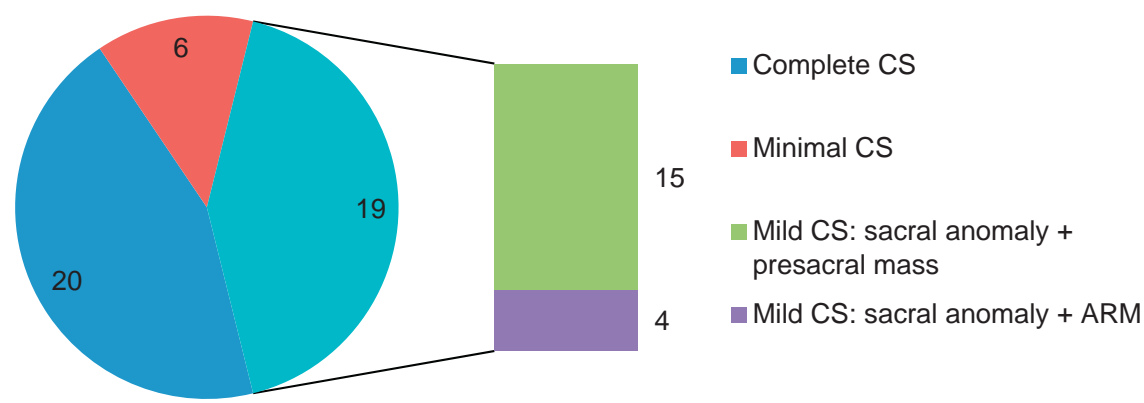

Fig. 1. Distribution of CS subtypes. [CS = Currarino Syndrome; ARM = anorectal malformation].

and trying to understand whether an association could be observed between the presence of a genetic defect and a more severe CS phenotype.

As previously reported by some Authors [9] and differently from what stated by others [10] there was no difference between male and female frequency in our series.

Although CS is well described in literature and it often shows signs at birth (such as ARM, some spinal dysraphisms, etc.), an early diagnosis at birth or by the first month of life - is still rarely achieved. In our series, almost half of the patients have been diagnosed with CS after 1 year of age and only $11 / 47$ (23.5\%) by the first month of life. Different factors could be responsible for this delay: most of the phenotypical components can be asymptomatic during the first phases of life; sacral X-ray and/or abdominal imaging might not be routinely performed in every neonate born with ARM, impeding the timely diagnosis of a sacral anomaly or a presacral mass; familial cases might be unrecognized because of the low penetrance of the syndrome. Although prenatal US can identify presacral masses, bowel hyperechogenicity or distension in case of obstruction from an ARM, or other associated malformations, the prenatal diagnosis of a CS remain an exceptional occurrence $[8,11]$. The genetic testing, if performed, may allow the diagnosis [12], as it happened in 2 of our patients. These tests, however, although CS has been recognized as a genetic condition, are not routinely performed in all Centers. In our series, 38 out of 45 patients ( $85 \%$ ) underwent a genetic

Table 1

Currarino phenotype: distribution and characterization of the triad elements.

\begin{tabular}{lll}
\hline Type of anomaly & $\begin{array}{l}\text { No. of } \\
\text { patients (\%) }\end{array}$ & $\begin{array}{l}\% \text { of the } \\
\text { entire series }\end{array}$ \\
\hline Sacral anomaly: & 45 & $100 \%$ \\
\hline Type I & - & - \\
Type II & - & - \\
Type III (subtotal sacral agenesis with S1 present) & 12 & $26.7 \%$ \\
Type IV (hemisacrum) & 30 & $66.7 \%$ \\
Type V (coccyx agenesis) & 3 & $6.6 \%$ \\
Anorectal malformation: & 24 & $53 \%$ \\
\hline & & \\
Recto-perineal fistula & $12(50 \%)$ & $27 \%$ \\
Anorectal stenosis & $5(21 \%)$ & $11 \%$ \\
Rectal stenosis & $3(12.5 \%)$ & $6.7 \%$ \\
Imperforate anus without fistula & $2(8 \%)$ & $4.5 \%$ \\
Recto-urethral fistula & $1(4 \%)$ & $2 \%$ \\
Recto-vestibular fistula & $1(4 \%)$ & $2 \%$ \\
Presacral mass: & 35 & $78 \%$ \\
\hline Mature teratoma & & \\
Anterior meningocoele & $17(48.5 \%)$ & $38 \%$ \\
Epidermoid cysts & $6(17 \%)$ & $13 \%$ \\
Lipomas & $2(6 \%)$ & $4.5 \%$ \\
Mixed teratoma & $2(6 \%)$ & $4.5 \%$ \\
Mixed masses & $1(3 \%)$ & $2 \%$ \\
& $7(20 \%)$ & $15.5 \%$ \\
\hline
\end{tabular}

study. In accordance with the literature, all familial cases presented a MNX1 mutation, while it could be detected in the $44 \%$ of the sporadic ones; this percentage is slightly higher than previously reported in sporadic CS $(30 \%,[3,13])$, probably due to both the high rate of patients tested in our series and the lack of a proper familial screening in many of them. Sporadic cases that turned out to be familial after proper genetic testing of the relatives have been described in literature [14,15]. We firmly believe that the genetic analysis is a necessary step in the diagnostic protocol of CS, not only in the proband but also in his/her relatives, to identify silent CS cases that could be diagnosed only in a later period and possibly avoid severe complications such as infection or malignant evolution of the presacral mass or neurologic consequences deriving from misdiagnosed neural tube defects.

The classification of CS in 3 subtypes was first reported by Martucciello et al. in 2004 [2], but the incidence of each type has never been described in a large series. In our multicentre study we found that the complete form is the most frequent, accounting for 20 cases, that is the $44.5 \%$ of the entire group (Fig. 1 ); a similar number of patients showed the Mild form (19 cases, $42.2 \%$ ), the majority of them presenting with a sacral anomaly associated to a presacral mass (15 cases, $33 \%$ of the entire series) and 4 (9\%) with a sacral anomaly associated to an ARM. The Minimal CS was found in 6 patients only (13.3\%), representing the least numerous phenotypical subtype. In all patients with Minimal CS the sacral anomaly was type IV. Although other degrees of sacral hypoplasia can be present in Mild and Complete CS types, we believe that hemisacrum alone should be considered diagnostic when not associated to other elements of the triad. This is particularly true when the patient with a sacral anomaly has a negative genetic test, like in 5 patients of our series (Table 4): in the absence of a MNX1 mutation, Minimal CS can be diagnosed only in the presence of hemisacrum or sickle shaped sacrum. Considering our whole series, hemisacrum is the most frequent sacral anomaly, identified in the $66.7 \%$ of the patients, followed by Pang's type III and V. The most severe forms, i.e. total sacral agenesis with (type I) or without (type II) involvement of lumbar vertebrae were not reported in our series. We recommend to perform a plain X-ray of the sacrum in the presence of: ARM, presacral mass, unexplained severe constipation and in families with history of CS.

The second most frequent element of the triad is the presacral mass, which accounts for the $78 \%$ of the entire series. Presacral mass is more frequent than ARM in Mild CS (15 vs. 4 patients). When studying a child with a presacral mass, both a sacral anomaly and a misdiagnosed ARM (i.e. mild anorectal or rectal stenosis) have to be searched for. Mature teratoma is the most frequent histological type, but many others can be diagnosed, like anterior menigocoeles, epidermoid cysts, lipomas, mixed teratomas and a combination of the previous entities (Table 1). Although we did not identify any malignancy in our series, malignant lesions or a malignant evolution of a benign condition have 
Table 2

Currarino phenotype: associated anomalies.

\begin{tabular}{|c|c|c|c|}
\hline Type of associated anomaly & $\begin{array}{l}\text { Tot. (\% of the } \\
\text { entire series) }\end{array}$ & Description & N. (\% of the entire series) \\
\hline \multirow[t]{11}{*}{ Spinal dysraphisms } & \multirow[t]{11}{*}{$29(64.5 \%)$} & Tethered cord & $12(27 \%)$ \\
\hline & & Tethered cord + Filum lipoma & $5(11 \%)$ \\
\hline & & Filum lipoma & $3(6.7 \%)$ \\
\hline & & Tethered cord + lipomyelocoele & $2(4.5 \%)$ \\
\hline & & Hydrosyringomyelia & $1(2 \%)$ \\
\hline & & Tethered cord + hydrosyringomyelia & $1(2 \%)$ \\
\hline & & Diastematomyelia & $1(2 \%)$ \\
\hline & & Hemimyelocystocoele + Chiari 2 & $1(2 \%)$ \\
\hline & & Chiari $1+$ Tethered Cord & $1(2 \%)$ \\
\hline & & Tethered cord + Filum lipoma + hydrosyringomyelia & $1(2 \%)$ \\
\hline & & Caudal regression & $1(2 \%)$ \\
\hline \multirow[t]{12}{*}{ Urological anomalies } & \multirow[t]{12}{*}{$15(33 \%)$} & Neurogenic bladder & $2(4.5 \%)$ \\
\hline & & Double moiety & $2(4.5 \%)$ \\
\hline & & VUR & $2(4.5 \%)$ \\
\hline & & Cryptorchidism & $1(2 \%)$ \\
\hline & & UTI & $1(2 \%)$ \\
\hline & & Renal hypodysplasia & $1(2 \%)$ \\
\hline & & Horseshoe kidney & $1(2 \%)$ \\
\hline & & Urethral stenosis & $1(2 \%)$ \\
\hline & & Horseshoe kidney + Renal Hypodysplasia + VUR & $1(2 \%)$ \\
\hline & & Renal Hypodysplasia + Ureteral Duplication + VUR + Neurogenic Bladder & $1(2 \%)$ \\
\hline & & Horseshoe kidney + VUR + Neurogenic Bladder & $1(2 \%)$ \\
\hline & & VUR + Hypospadias & $1(2 \%)$ \\
\hline \multirow[t]{4}{*}{ Cerebral anomalies } & \multirow[t]{4}{*}{$7(15.5 \%)$} & Microcephaly & $2(4.5 \%)$ \\
\hline & & Microcephaly + Holoprosencephaly & $2(4.5 \%)$ \\
\hline & & Microcephaly + hypoplasia of the corpus callosus and optical nerves + neurodevelopmental delay & $1(2 \%)$ \\
\hline & & Neurological impairment & $1(2 \%)$ \\
\hline \multirow[t]{6}{*}{ Skeletal anomalies } & \multirow[t]{6}{*}{$7(15.5 \%)$} & Clinodactyly fifth finger & $2(4.5 \%)$ \\
\hline & & Suprannumerary finger & $1(2 \%)$ \\
\hline & & Bilateral clubfoot & $1(2 \%)$ \\
\hline & & 11 right ribs & $1(2 \%)$ \\
\hline & & Micrognatia & $1(2 \%)$ \\
\hline & & Vertebral dysmorphism (cervical) & $1(2 \%)$ \\
\hline \multirow[t]{4}{*}{ Cardiac anomalies } & \multirow[t]{4}{*}{$4(9 \%)$} & Patent foramen ovale & $1(2 \%)$ \\
\hline & & Rhythm anomalies & $1(2 \%)$ \\
\hline & & Tetralogy of Fallot & $1(2 \%)$ \\
\hline & & Mesocardia + Persistent left superior vena cava draining into the coronary sinus & $1(2 \%)$ \\
\hline Dysganglionosis & $3(6,7 \%)$ & Hirschsprung's disease & $3(6,7 \%)$ \\
\hline Gynecological anomalies & $2(4,5 \%)$ & Bicornuate uterus & $2(4.5 \%)$ \\
\hline \multirow{9}{*}{ Other } & \multirow{9}{*}{$9(20 \%)$} & Choanal stenosis, hypertelorism, absence of the superior labial frenulum & $1(2 \%)$ \\
\hline & & $\begin{array}{l}\text { Coloboma of iris and retina, macrotia, solitary median maxillary central incisor, } \\
\text { afasia, hypotonia }\end{array}$ & $1(2 \%)$ \\
\hline & & Bilateral inguinal hernia & $1(2 \%)$ \\
\hline & & Bilateral hypoacusis & $1(2 \%)$ \\
\hline & & Sacral angioma & $1(2 \%)$ \\
\hline & & Sacral dimple & $1(2 \%)$ \\
\hline & & $\mathrm{X}$-linked ichthyosis & $1(2 \%)$ \\
\hline & & Bilateral epicantus & $1(2 \%)$ \\
\hline & & Preputial cyst & $1(2 \%)$ \\
\hline Total & $38(84.5 \%)$ & & \\
\hline
\end{tabular}

been reported in literature in association with CS, in the form of leiomyosarcoma, malignant teratoma, ectopic nephroblastoma, neuroendocrine tumors, with an estimated incidence of $1 \%[2,8-10,16]$. This is one of the main reasons why an early diagnosis of CS is advocated. A presacral mass can also produce an abscess and may primarily present as a gluteal mass or fistula, like in one of our patients; the incidence of perianal sepsis is reported as high as $11 \%$ in some series [8]. A fearsome complication can be the bacterial meningitis secondary to a presacral abscess $[2,10,12,17]$.

Table 3

Relationship between Currarino subtype and number of associated anomalies ( $p=0.5102$, chi-squared test).

\begin{tabular}{lclcc}
\hline $\begin{array}{l}\text { Currarino } \\
\text { subtype }\end{array}$ & Total & $\begin{array}{l}\text { No associated } \\
\text { anomalies }\end{array}$ & $\begin{array}{l}1 \text { associated } \\
\text { anomaly }\end{array}$ & $\begin{array}{l}\geq 2 \text { associated } \\
\text { anomalies }\end{array}$ \\
\hline Complete & 20 & $5(25 \%)$ & $6(30 \%)$ & $9(45 \%)$ \\
Mild & 19 & $2(10.5 \%)$ & $6(31.6 \%)$ & $11(57.9 \%)$ \\
Minimal & 6 & 0 & $3(50 \%)$ & $3(50 \%)$ \\
Total & 45 & $7(15.5 \%)$ & $15(33.5 \%)$ & $23(51 \%)$ \\
\hline
\end{tabular}

Almost half of CS patients in our series (53\%) were affected by ARM. It is more common in the context of a Complete CS, although it can be present in association with a sacral anomaly only (9\%). As previously reported $[2,18]$, the most frequent ARM in CS is the recto-perineal fistula, but other forms have been identified. Eight patients (8/24, 33\%), presented the so-called "funnel anus" a characteristic feature of CS, that is a funnel-shaped anal canal, with a stenosis at the level of the dentate line [19], referred to as "anorectal stenosis" or "rectal stenosis" in our series. Constipation is a common finding in the presence or absence of an

Table 4

Relationship between Currarino subtype and presence of MNX1 mutation ( $p=0.0085$, chi-squared test).

\begin{tabular}{lcc}
\hline Currarino subtype & MNX1 + & MNX1- \\
\hline Complete & 13 & 2 \\
Mild & 9 & 8 \\
Minimal & 1 & 5 \\
Tot & 23 & 15 \\
\hline
\end{tabular}


Table 5

Genotype and phenotype details of the 2 patients with CS-holoprosencephaly.

\begin{tabular}{|c|c|c|}
\hline & Patient 1 & Patient 2 \\
\hline Sex & $\mathrm{F}$ & $\mathrm{F}$ \\
\hline Age at diagnosis (years) & 4 & 3 \\
\hline Inheritance & Sporadic & Sporadic \\
\hline Genetic alteration & $\begin{array}{l}\text { Chromosome 7q microdeletion, including } \\
\text { MNX1 and SHH genes; other genes included: } \\
\text { PAXIP1, HTR5A, EN2, LMBR1, DPP6 }\end{array}$ & arr 7q36.1q36.2 × 3,7q36.2q36.3 × 1 \\
\hline Sacral anomaly & Type III & Type III \\
\hline Presacral mass & Teratoma + anterior meningocoele & Mixed teratoma \\
\hline ARM & - & - \\
\hline CS type & Mild CS & Mild CS \\
\hline Spinal dysraphisms & Tethered cord, filum lipoma & Tethered cord, filum lipoma \\
\hline Urological anomalies & - & Horseshoe kidney, VUR, hyperreflexic bladder \\
\hline Cerebral anomalies & $\begin{array}{l}\text { Microcephaly (microcephaly as microform } \\
\text { holoprosencephaly without MRI alterations) }\end{array}$ & $\begin{array}{l}\text { Microcephaly, holoprosencephaly, } \\
\text { neurological impairment, MRI alterations }\end{array}$ \\
\hline Skeletal anomalies & - & - \\
\hline Cardiac & - & $\begin{array}{l}\text { Mesocardia + persistent left superior vena cava } \\
\text { draining into the coronary sinus }\end{array}$ \\
\hline Dysganglionosis & - & - \\
\hline Gynecological & - & - \\
\hline Other & - & Bilateral hypoacusis \\
\hline
\end{tabular}

ARM [19-21]; although it can be ascribed to various factors, we believe, in accordance with previous reported data [2,22], that a dysganglionosis research should be performed in every CS patient affected by constipation. Three patients in our series resulted positive for Hirschsprung's disease (6.7\%), but this incidence could be underestimated, because a dysganglionosis research was not routinely offered to CS constipated patients in all the participating Centers.

In the majority of CS patients (84.5\%) one or more associated anomalies, in addition to the classical triad, was identified (Table 2).

The most frequent were spinal dysraphisms that require a prompt diagnosis and, frequently, a surgical correction to prevent their progressive behavior and to reduce the significant morbidity that can occur (mainly sphincter dysfunction with symptoms of constipation and bladder disfunction) $[4,8,10]$.

Cerebral anomalies were also frequent in our series, with an incidence of $15.5 \%$. Microcephaly was the most frequent condition ( 5 patients, $11 \%$ of the entire series), followed by holoprosencephaly (2), neurodevelopmental delay (2) and hypoplasia of the corpus callosus and optical nerves (1). Holoprosencephaly results from incomplete midline cleavage of the prosencephalon and is the most common forebrain defect in humans [23]. The association between CS and holoprosencephaly has already been described as a very rare condition due to a deletion in the long arm of chromosome 7 , in the $7 q 36$ region, including both MNX1 and SHH (sonic hedgehog) genes [23]; this alteration was detected in both our patients with holoprosencephaly. As recently underlined by Cuturilo et al. [24], intellectual disability is frequent in CS patients with larger $7 \mathrm{q}$ deletions, but absent in those carrying intragenic MNX1 mutations; we could verify this genotype correspondence in both our patients affected by neurodevelopmental delay, who showed 7q deletion at chromosomal microarray (Table 6).

One third of CS patients were affected by a urological pathology, in the form of neurogenic bladder, double moiety, VUR, cryptorchidism, recurrent UTIs, renal hypodysplasia, horseshoe kidney, urethral stenosis, ureteral duplication, hypospadias. In spite of the high incidence of urological anomalies, already reported by other Authors [20], recent experiences show that the urological outcome seems to be good in the majority of patients [18].

Skeletal defects were detected with the same percentage as cerebral anomalies (15.5\%). They mainly affected upper or lower extremities, but also vertebrae, ribs and facial bones.

As in other syndromic conditions, cardiac anomalies were diagnosed, both major and minor ones, but were less represented than other conditions ( 4 patients, $9 \%$ of the entire series).

The least numerous associated anomalies were bicornuate uterus ( 2 patients) and other minor conditions, as reported in Table 2.

Table 6

Genotype and phenotype details of the 2 patients with neurodevelopmental delay.

\begin{tabular}{|c|c|c|}
\hline & Patient 1 & Patient 2 \\
\hline Sex & M & $\mathrm{F}$ \\
\hline Age at diagnosis (years) & 5 & 3 \\
\hline Inheritance & Sporadic & Sporadic \\
\hline Genetic alteration & 2 q37.3 dup; $7 q 36.2-q 36.3$ del & $\operatorname{arr} 7 \mathrm{q} 36.1 \mathrm{q} 36.2 \times 3,7 \mathrm{q} 36.2 \mathrm{q} 36.3 \times 1$ \\
\hline Sacral anomaly & Type IV & Type III \\
\hline Presacral mass & - & Mixed teratoma \\
\hline ARM & - & - \\
\hline CS type & Minimal CS & Mild CS \\
\hline Spinal dysraphisms & - & Tethered cord, filum lipoma \\
\hline Urological anomalies & Urethral stenosis & Horseshoe kidney, VUR, hyperreflexic bladder \\
\hline Cerebral anomalies & $\begin{array}{l}\text { Microcephaly, hypoplasia of the corpus callosus and } \\
\text { optical nerves, neurodevelopmental delay }\end{array}$ & $\begin{array}{l}\text { Microcephaly, holoprosencephaly, } \\
\text { neurological impairment, MRI alterations }\end{array}$ \\
\hline Skeletal anomalies & - & - \\
\hline Cardiac & - & $\begin{array}{l}\text { Mesocardia }+ \text { persistent left superior vena } \\
\text { cava draining into the coronary sinus }\end{array}$ \\
\hline Dysganglionosis & - & - \\
\hline Gynecological & - & - \\
\hline Other & $\begin{array}{l}\text { Coloboma of iris and retina, macrotia, solitary median } \\
\text { maxillary central incisor, afasia, hypotonia }\end{array}$ & Bilateral hypoacusis \\
\hline
\end{tabular}


The number and variety of conditions associated to CS is impressive, particularly considering that more than half of the patients in our series presented 2 or more associated anomalies (Table 3 ) and only a small minority (about 15\%) did not present any. Nevertheless, the number of associated anomalies does not seem to correlate with the severity of the CS phenotype as determined by the 3 clinical subtypes (Table 3). On the contrary, from our analysis the severity of the CS subtype seems to be related to the presence of a MNX1 anomaly (see Table 4, $p=0.0085$, chi-squared test).

The reason could be that MNX1 gene is mainly responsible of the expression of the triad elements, while the associated anomalies could be determined by genes sited on other loci, such as SHH gene or others, such as LMBR1 for limb anomalies [23], DPP6 for cardiac rhythm disturbances, etc. (Table 5), as demonstrated by Cuturilo et al. [24]. Although it has been hypothesized that CS might depend not only on MNX1 mutations but also on the effect of other yet unknown genes [3,25], MNX1 might be the most important responsible of the expression and the severity of the main phenotypical triad. In light of these considerations, genetic testing is of utmost importance in all CS patients and their relatives, both in postnatal and prenatal settings, to guide the diagnostic and therapeutic pathways, to gather information about the severity of the phenotype that a fetus might express and to collect data about new genes that might be involved in CS characterization.

Our experience has some limits that need to be addressed. First of all, this is a retrospective data collection, based on clinical records and gathered by a different operator in each Centre; although a data collection sheet has been created to systematize the work, it has been used only after the patients had been studied according to each Centre clinical pathway. This also implies that the study of some patients results incomplete from the records available, particularly for the genetic aspects, due to the lack of a systematic approach to CS patients in every Centre. Then, the calculated incidences of some associated conditions might be inaccurate, particularly for those anomalies that do not have a clinical relevance. Nevertheless, the multicentre collection and the relatively high number of cases make the study interesting at least for the main CS-associated conditions. Further prospective multicentre studies, with a special attention to the genetic analysis, would be required to more accurately address the issues treated.

In light of our findings, a comprehensive diagnostic protocol for CS patients should include: in-depth collection of personal and familial data; thorough clinical evaluation including rectal examination; sacral X-ray; sacral ultrasound (US), when appropriate for age [26], to study the caudal spinal cord; abdominal US; abdomen, pelvis, spine and brain MRI; MCUG, urodynamic tests or other urological studies when indicated; cardiac evaluation with cardiac US; chest and spine X-ray for ribs and vertebral defects; neurological consult; genetic consult, comprehensive of genetic test, pedigree of the family and clinical evaluation of relatives, with prescription of radiological and genetic studies when required; rectal suction biopsy for dysganglionosis research in severely constipated patients; other specific consults on the basis of the clinical scenario (neurosurgical, orthopedic, gynaecologic, ophthalmologic, etc.). Family follow-up is also useful to establish the oncological risk for each family group, with the support of specific clinical and instrumental evaluations (physical exam including rectal examination, dosage of alfa-fetoprotein, US/MRI when indicated).

A multidisciplinary approach, always completed by a genetic evaluation, is mandatory to correctly manage each patient and to reduce the morbidity and mortality related to CS.

\section{Conclusions}

The presence of a MNX1 mutation seems to correlate with a more severe CS phenotype. MNX1 gene seems the main responsible of the expression and the severity of the CS triad, while the associated anomalies appear to be mainly determined by genes sited on different loci. A thorough multidisciplinary diagnostic overview of CS patients should always include genetic counseling and analysis, both in postnatal and prenatal settings, to try to gather information about the severity of the phenotype, to guide the diagnostic and therapeutic pathways, and to collect data about new genes that might be involved in CS characterization.

\section{References}

[1] Currarino G, Coln D, Votteler T. Triad of anorectal, sacral, and presacral anomalies. AJR Am J Roentgenol 1981;137(2):395-8.

[2] Martucciello G, Torre M, Belloni E, et al. Currarino syndrome: proposal of a diagnostic and therapeutic protocol. J Pediatr Surg 2004;39(9):1305-11.

[3] Merello E, De Marco P, Ravegnani M, et al. Novel MNX1 mutations and clinical analysis of familial and sporadic Currarino cases. Eur J Med Genet 2013;56(12):648-54.

[4] Pang D. Sacral agenesis and caudal spinal cord malformations. Neurosurgery 1993; 32(5):755-78.

[5] Belloni E, Martucciello G, Verderio D, et al. Involvement of the HLXB9 homeobox gene in Currarino syndrome. Am J Hum Genet 2000;66(1):312-9.

[6] Yates VD, Wilroy RS, Whitington GL, et al. Anterior sacral defects: an autosomal dominantly inherited condition. J Pediatr 1983;102(2):239-42.

[7] Ross AJ, Ruiz-Perez V, Wang Y, et al. A homeobox gene, HLXB9, is the major locus for dominantly inherited sacral agenesis. Nat Genet 1998;20(4):358-61.

[8] Lynch SA, Wang Y, Strachan T, et al. Autosomal dominant sacral agenesis: Currarino syndrome. J Med Genet 2000;37(8):561-6.

[9] Crétolle C, Zérah M, Jaubert F, et al. New clinical and therapeutic perspectives in Currarino syndrome (study of 29 cases). J Pediatr Surg 2006;41(1):126-31.

[10] Yoshida A, Maoate K, Blakelock R, et al. Long-term functional outcomes in children with Currarino syndrome. Pediatr Surg Int 2010;26(7):677-81.

[11] Crétolle C, Sarnacki S, Amiel J, et al. Currarino syndrome shown by prenatal onset ventriculomegaly and spinal dysraphism. Am J Med Genet A 2007;143A(8):871-4.

[12] Kim SH, Paek SH, Kim HY, et al. Currarino triad with Müllerian duct anomaly in mother and daughter without MNX1 gene mutation. Ann Surg Treat Res 2016; 90(1):49-52.

[13] Kim IS, Oh SY, Choi SJ, et al. Clinical and genetic analysis of HLXB9 gene in Korean patients with Currarino syndrome. J Hum Genet 2007;52(8):698-701.

[14] Zu S, Winberg J, Arnberg F, et al. Mutation analysis of the motor neuron and pancreas homeobox 1 (MNX1, former HLXB9) gene in Swedish patients with Currarino syndrome. J Pediatr Surg 2011;46(7):1390-5.

[15] Markljung E, Adamovic T, Cao J, et al. Novel mutations in the MNX1 gene in two families with Currarino syndrome and variable phenotype. Gene 2012;507(1):50-3.

[16] Dirix M, van Becelaere T, Berkenbosch L, et al. Malignant transformation in sacrococcygeal teratoma and in presacral teratoma associated with Currarino syndrome: a comparative study. J Pediatr Surg 2015;50(3):462-4.

[17] Fleury J, Picherot G, Cretolle C, et al. Currarino syndrome as an etiology of a neonatal Escherichia coli meningitis. J Perinatol 2007;27(9):589-91.

[18] Pio L, Piatelli G, Rossi A, et al. Urological outcome in patients with Currarino syndrome. J Pediatr Surg 2014;49(11):1643-6.

[19] Monclair T, Lundar T, Smevik B, et al. Currarino syndrome at Rikshospitalet 19612012. Tidsskr Nor Laegeforen 2013;133(22):2364-8.

[20] Lynch SA, Bond PM, Copp AJ, et al. A gene for autosomal dominant sacral agenesis maps to the holoprosencephaly region at 7q36. Nat Genet 1995;11(1):93-5.

[21] Emans PJ, Kootstra G, Marcelis CL, et al. The Currarino triad: the variable expression. J Pediatr Surg 2005;40(8):1238-42.

[22] Ohno K, Nakamura T, Azuma T, et al. Familial Currarino syndrome associated with Hirschsprung disease: two cases of a mother and daughter. J Pediatr Surg 2013; 48(1):233-8.

[23] Coutton C, Poreau B, Devillard F, et al. Currarino syndrome and HPE microform associated with a 2.7-Mb deletion in 7q36.3 excluding SHH Gene. Mol Syndromol 2014; 5(1):25-31.

[24] Cuturilo G, Hodge JC, Runke CK, et al. Phenotype analysis impacts testing strategy in patients with Currarino syndrome. Clin Genet 2016;89(1):109-14.

[25] Garcia-Barceló MM, Lui VC, So MT, et al. MNX1 (HLXB9) mutations in Currarino patients. J Pediatr Surg 2009;44(10):1892-8.

[26] Schenk JP, Herweh C, Günther P, et al. Imaging of congenital anomalies and variations of the caudal spine and back in neonates and small infants. Eur J Radiol 2006;58(1):3-14. 